UDC 676.164.8 544.723.2:547.556.9

\title{
STUDY OF TECHNICAL CELLULOSE AS A MATRIX-SORBENT TO DEVELOP EXPRESS ANALYTIC SYSTEM FOR WATER SAFETY CONTROL
}

\author{
(C) T.I. Maslakova ${ }^{1}$, A.V. Vurasko ${ }^{*}$, I.G. Pervova ${ }^{1}$, P.A. Maslakov ${ }^{1}$, L.V. Aleshina ${ }^{2}$, I.O. Shapovalova ${ }^{1}$ \\ ${ }^{1}$ Ural State Forestry University, ul. Sibirskiy trakt, 37, Yekaterinburg, 620100 \\ (Russia), e-mail: vurasko2010@yandex.ru \\ 2 Ural State Economic University, ul. 8-Marta, 62, Yekaterinburg, 620102 (Russia)
}

\begin{abstract}
The study presented by the authors is devoted to the study of the properties and the possibility of using technical cellulose from non-wood plant raw materials as a solid-phase matrix to obtain solid-phase reactive indicator systems by the following methods: synthesis method on the base of a hetarylformazane immobilized on a cellulose matrix and development of analytical systems based on preconcentration of the determined metal ion by a matrix with subsequent its «revealing» by the formazan («revealing» method).

The article focuses on determination of optimal combinations of chromogenic organic reagents (hetarylformazanes) and cellulose-based matrices for developing solid-phase reaction-based indicator systems. Adsorption features of formazan reagents onto cellulose matrices was studied. It has been established the relation between the reagent molecule structure, composition of cellulose matrix and analytical properties of the test-systems synthesized to determine metal ions. Different approaches were developed and applied to reveal the visually observable and easily measured effect due to cellulose properties as well as properties of hetarylformazanes fixed on the surface of the matrix. This fact allows to control sensitivity and selectivity of solid-phase reactive indicator systems for water quality assessment.

Keywords: rice husk, oat straw, cellulose matrix composition, modified sorbents, water safety control, hetarylformazans, solid-phase reactive indicator system, mercury, test-systems, express analytic system.

The study was carried out with financial support of the Ministry of Science and Higher Education of the

Russian Federation within the scope of a scientific project «FEUG-2020-0013».
\end{abstract}

\section{Introduction}

Technical cellulose and its processed products are becoming more widespread as raw materials for the chemical, pharmaceutical, food, defense industries, as well as for solving environmental problems. At present, much attention is paid to obtaining affordable sorbents based on natural materials, the functional groups of which are capable to retain reagents on the surface for visual and coloristic determination of the content of metal ions in natural and waste waters [1]. The technical cellulose obtained from wood by the traditional method does not possess the required set of properties to obtain effective sorption materials, while cellulose from non-wood plant raw materials

Maslakova Tatiana - PhD (Chemical), Associate professor of the Department of physical and chemical technologies in environmental engineering, e-mail: maslakovati@gmail.com Vurasko Alesya - DSc (Technical), Professor, Head of the Department technology of pulp and paper industries and polymer processing, e-mail: vurasko2010@yandex.ru Pervova Inna - DSc (Chemical), Professor of the Department of physical and chemical technologies in environmental engineering, e-mail: biosphera@usfeu.ru Maslakov Pavel - Assistant of the Department of physical and chemical technologies in environmental engineering, e-mail:pashalx@gmail.com Aleshina Ludmila - Associate professor of the Department of physics and chemistry, e-mail: alv@usue.ru

Shapovalova Irina - applicant, e-mail: artistsky@yandex.ru has a lower degree of crystallinity, contains a sufficient amount of hemicelluloses, is easier to delignify and bleach, the raw materials for obtaining are reproducible annually. These qualities are important in the development of sorption materials for the detection of toxic components (for example, heavy metals) in natural and waste waters generated in the course of human production activities. In terms of its component composition, rice straw is similar to softwood (Pinus sibirica), oat straw is close to hardwood (Betula pubescens). Their distinctive features are the high content of minerals of 13.7 and $5.8 \%$, respectively. Rice husk is characterized by a low content of cellulose, a high

${ }^{*}$ Corresponding author. 
content of lignin, as well as minerals and substances soluble in water [2], which allows us to conclude that it is possible to use the selected types of raw materials to obtain technical cellulose by the oxidative-organosolvent method and sorption materials from it.

Express testing is one of the best solutions to the determining trace quantities of contaminants in water. Special attention is drawn to development of methods combining preliminary solid phase extraction with the following separation of contaminants from matrices and the subsequent rapid determination of them by such analytical techniques as flame atomic absorption spectrometry (FAAS) and inductively coupled plasma optical emission spectroscopy (ICP-OES). When preconcentrating trace amounts of the contaminants, sensitivity and rate of the analysis are influenced by the sorption kinetic parameters and sorption characteristics of the sorption materials applied as matrix-carriers. The materials are capable both to modification of a surface by organic reagents [3-6] and for selective interaction with ions of metals [7].

When selecting the matrixes, the main characteristics are following: the well-developed material surface, a variety of use, mechanical durability, and high capacity. Such matrix-carriers as silica gel $[3,5,7]$ materials modified with organic chelating agents $[3,4,7]$ are widely used.

A special focus is on the modification of sheet-shaped cellulose sorbents produced via oxygen-organosolv treatment of rice husk and oat straw $[8,9]$. Such physical and chemical properties of the sorbents as high hydrophilic property, $-\mathrm{COOH},-\mathrm{OH},-\mathrm{CO}$-containing reactive groups, large amorphous regions in cellulose, and controlled initial neutral colours contribute to development of hybrid methods for the analysis which provide separation, concentration, visual and optical detections during the same analytical procedure.

In the presented research, a range of combinations of chromogenic reagents and cellulose matrixes had been studied for development of solid-phase reactive indicator systems (SPRIS). Hetarylformazans [10-12] were used as chromophoric reagents. High variability of substituents and high flexibility of covalent bonds in the formazan chain make it available to synthesize sorbents with predetermined operational characteristics. Cellulose properties as well as properties of hetarylformazanes fixed on the surface of the matrix in different tautomeric forms directly influence on analytical properties of the sorbents. This fact allows predicting their using at the stage of synthesis. The presence of the azohydrazone group and additional coordination center in the polydentate formazan structure is responsible for both intense light absorption in the visible spectrum and significant bathochromic shift effect emerging when interacting the cellulose matrix with toxic metal ions. It is the chromogenic characteristics of formazans that make it available to synthesize solid-phase reactive indicator systems on the base of cellulose matrices for water analysis $[10,11]$.

The study presented by the authors is devoted to the study of the properties and the possibility of using technical cellulose from non-wood plant raw materials as a solid-phase matrix to obtain solid-phase reactive indicator systems by the following methods:

$-1^{\text {st }}$ method: synthesis of SPRIS on the base of a hetarylformazane immobilized on a cellulose matrix;

$-2^{\text {nd }}$ method: developing analytical systems based on preconcentration of the determined metal ion by a matrix with subsequent its «revealing» by the formazan («revealing» method).

Developed express analytical systems (SPRIS) will be tested to develop methods for the visual determination of toxic metals in aqueous media.

\section{Experimental}

Cellulose matrices. Production of plant-based pulp was carried out in two stages: the first stage - alkaline treatment [13], the second stage - oxygen-organosolv pulping [14, 15]. After delignification, the pulp was washed with distilled water and ground. Then different compositions were composed and further pulp sheets were produced on the base of the compositions. The obtained sheets were used as cellulose matrices. Cellulose matrices made of rice husks (RH) exhibit excellent sorption properties, but poor strength properties because the matrices consist of short fibres. To enhance the strength and keep the sorption properties of cellulose matrices, it was composed a composition based on the cellulose made of rice husk and oat straw. Because oat straw cellulose consists of longer bast fibres, it was used as reinforcement in the composition. As it was established [13] the best composition ratio is $50 \%$ rice husk cellulose to $50 \%$ oat straw cellulose (RHOS). The whiteness of the obtained samples meets the requirements for matrices for reaction indicator systems [16]. Structure parameters and properties of the cellulose matrices are presented in Table 1. 
Table 1. Structure parameters and properties of the cellulose matrices

\begin{tabular}{l|c|c|c|c|c}
\hline Matrix & Cellulose matrix composition (freeness, $\left.{ }^{\circ} \mathrm{SR}\right)$ & $\begin{array}{c}\text { Mass, } \\
\mathrm{g} / 1 \mathrm{~m}^{2}\end{array}$ & $\begin{array}{c}\text { Thickness, } \\
\mathrm{mm}\end{array}$ & $\begin{array}{c}\text { Whiteness, } \\
\%,\end{array}$ & $\begin{array}{c}\text { Carboxyl groups } \\
\text { content, mmol } / \mathrm{g}\end{array}$ \\
\hline RHOS & $50 \%$ oat straw $\left(50^{\circ} \mathrm{SR}\right)+50 \%$ rice husk $\left(30^{\circ}\right.$ & $100 \pm 1.0$ & $0.23 \pm 0.2$ & $81.2 \pm 0.5$ & 0.401 \\
$\mathrm{RH}$ & $\begin{array}{c}\mathrm{SR}) \\
\mathrm{RH}\end{array}$ & $160 \pm 1.5$ & $0.46 \pm 0.2$ & $82.7 \pm 0.5$ & 0.495 \\
\hline
\end{tabular}

Carboxyl groups content in cellulose matrices were determined by potentiometric titration of the acetic acid released after reaction between acid cellulose groups and calcium acetate.

Preparing the cellulose sorbents. The cellulose sorbents were synthesized by immobilizing hetarylformazanes on cellulose carrier matrices - RH and RHOS. To modify the cellulose matrices it was selected hetarylformazanes (I-IX) (Tab. 2) which react with bivalent metal ions with formation of deeply coloured complex compounds $[10,11,17,18]$. Immobilization of hetarylformazanes (I-IX) had been carried out under static conditions by the method of varying concentrations of formazanes in aqueous ethanol solutions $(10: 1)$ at $293 \mathrm{~K}$ for 40 minutes. The cellulose matrices were prepared by cutting from cellulose pulp sheets as squares sized $(15 \pm 1) \mathrm{mm}$, mass $(0.0248 \pm 0.0050) \mathrm{g}$. The matrices were placed into $20 \mathrm{~cm}^{3}$ of $(5.0-8.5) \cdot 10^{-5} \mathrm{~mol} / \mathrm{dm}^{3}$ formazan solution $(\mathrm{pH}$ (5.6 \pm 0.5$))$ put in $100 \mathrm{~cm}^{3}$ conical flask. The contents in the flask had been stirred for 40 minutes at room temperature. After decanting, the cellulose sorbents were placed on filter paper and dried in air. Properties of the formazanes (IIX) and formazan-based cellulose matrices 1-9 are presented in Table 2, 3.

Adsorption isotherms. The adsorbed amount of formazanes or metal ions was determined by the equation:

$$
a_{\max }=\frac{C_{0}-C_{f}}{m} \cdot V
$$

where $\mathrm{a}_{\max }$ - amount of formazanes or metal ions adsorbed per unit mass of the adsorbent, mol/g; $C_{0}$ and $C_{\mathrm{f}}-$ initial and finish concentrations of formazanes or metal ions in the solution, respectively, $\mathrm{mol} / \mathrm{dm}^{3} ; \mathrm{V}-$ volume of the solution, $\mathrm{dm}^{3} ; \mathrm{m}$ - mass of the adsorbent, $\mathrm{g}$.

The residual concentration of formazan in the solution was determined graphically according to the dependence of the optical density on the organic reagent concentration obtained by photometric method. The content of metal ions in the solution before and after sorption was determined by voltammetry. The average values of adsorption amounts were calculated for every concentration in three experiments.

Quantum chemical calculations. Quantum chemical calculations were carried out using Spartan'10 and Gaussian'08 software packages by the B3LYP density functional method with the $6-31 \mathrm{G}^{* *}$ basis. Atomic charges were determined using a modern adaptation of Millikan's oil drop experiment. GaussView software package was used for molecule modelling.

Calibration curves. The calibration curves were plotted using single-colored scales for the determination of metals, when optimized concentrating them onto the sorbents. The colored matrices were scanned and processed with Adobe Photoshop software. Determination of the color coordinates in the RGB system has revealed a linear relationship between G-coordinates and the metal ion concentrations.

\section{Results and discussion}

\section{Studies of modified cellulose-containing matrices}

Dependence of the adsorbed amount of hetarylformazanes (I-IX) on the nature of the cellulose matrix is shown in Figure 1. It was found that benzyl-benzimidazolyl-<diphenyl-pyrimidinylformazanes (V-IX) were effectively fixed and distributed on the cellulose matrix surface.

It was noticed the only RH matrix was uniformly stained due to the high content of epidermal fibres in outer layer of a seed. Epidermal fibres contain up to $30 \%$ mineral components by the end of the growing season [14, 19, 20]. While growing, two processes occur simultaneously within the cell wall: formation of the supramolecular structure of cellulose and accumulation of silica dioxide [21]. It results to deformation of cellulose crystal lattice during developing the cell and reduces its degree of crystallinity. In this regard, RH-cellulose matrices perform high sorption and absorption properties allowing uniform fixing the reagents onto the surface. 
Table 2. Hetarylformazanes for modification of the cellulose matrices

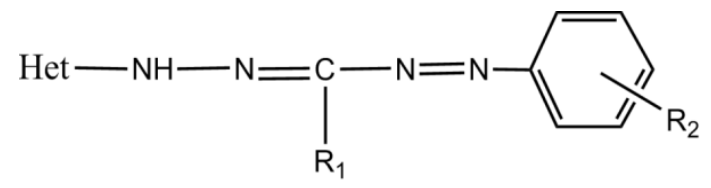

\begin{tabular}{|c|c|c|c|c|c|c|c|}
\hline $\begin{array}{c}\text { Compound } \\
\text { № }\end{array}$ & Het & $\mathrm{R}_{1}$ & $\mathrm{R}_{2}$ & $\begin{array}{c}\text { Compound } \\
\text { № }\end{array}$ & Het & $\mathrm{R}_{1}$ & $\mathrm{R}_{2}$ \\
\hline I & & $\mathrm{C}_{2} \mathrm{H}_{5}$ & $\mathrm{H}$ & VI & & $\mathrm{C}_{2} \mathrm{H}_{5}$ & $2-\mathrm{CH}_{3}$ \\
\hline II & & $\mathrm{C}_{2} \mathrm{H}_{5}$ & $2-\mathrm{CH}_{3}$ & VII & & $\mathrm{CH}_{3}$ & $\mathrm{H}$ \\
\hline III & & $\mathrm{C}_{2} \mathrm{H}_{5}$ & 4- $\mathrm{COOH}$ & VIII & & $\mathrm{CH}_{3}$ & $2-\mathrm{CH}_{3}$ \\
\hline IV & & $\mathrm{CH}\left(\mathrm{CH}_{3}\right)_{2}$ & $4-\mathrm{COOH}$ & IX & & $\mathrm{CH}_{3}$ & $4-\mathrm{COOH}$ \\
\hline V & & $\mathrm{C}_{2} \mathrm{H}_{5}$ & $\mathrm{H}$ & & & & \\
\hline
\end{tabular}

Table 3. Sorption properties of cellulose sorbents 1-9

\begin{tabular}{l|c|c|c|c|c|c|c|c|c}
\hline \multicolumn{1}{c|}{ Compound № } & I & II & III & IV & V & VI & VII & VIII & IX \\
\hline Sorbent № & 1 & 2 & 3 & 4 & 5 & 6 & 7 & 8 & 9 \\
$\mathrm{a}_{\max }, \mathrm{mmol} / \mathrm{kg}$ RH & 1.21 & 1.42 & 1.52 & 0.33 & 4.66 & 5.96 & 5.60 & 7.46 & 12.26 \\
$\mathrm{a}_{\max }, \mathrm{mmol} / \mathrm{kg}$ RHOS & - & - & - & - & 4.58 & 5.88 & 5.11 & 7.41 & 12.06 \\
\hline
\end{tabular}

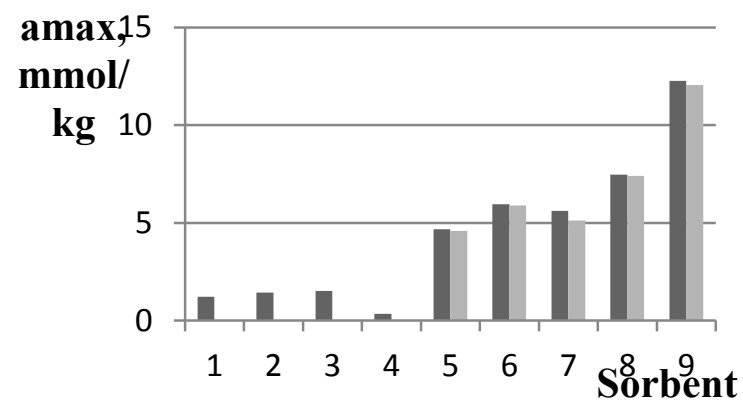

Fig. 1. The adsorbed amount of formazanes onto RH-cellulose matrix (black) and RHOS-cellulose matrix (grey)

As it has been shown the pattern of adsorption of formazanes onto RH- and RHOS-matrices depends on both the reagent structure and the composition of solid-phase carriers [22].

Since the hetarylformazanes analyzed can be in different tautomeric forms [10, 23], to determine the adsorption efficiency it was calculated values for the highest occupied molecular orbital energy Еном and lowest unoccupied molecular orbital energy E $_{\text {LUMO }}$ by the method of quantum chemical calculations using Spartan'10 and Gaussian'08 software packages by the B3LYP density functional method with the 6-31G** basis set [24]. The values $\mathrm{E}_{\mathrm{HOMO}}$ and $\mathrm{E}_{\mathrm{LUMO}}$, representing in fact the ionization potential and electron affinity in the framework of Koopmans' theorem, determine the «softness» of the molecule (S) and the higher the "softness" of the molecule, the more efficient the adsorption $[25,26]$.

According to the calculated values of S (Tab. 4), adsorption capacity of 1-phenyl formazanes is increasing in the series: diphenyl-pyrimidinyl-<benzyl-benzimidazolyl-<benzothiazolylformazanes; adsorption capacity of 14-carboxyphenyl formazanes is increasing in the series: diphenyl-pyrimidinyl-< benzothiazolylformazanes; and adsorption capacity of 1-2-tolyl derivatives is increasing in the series: diphenyl-pyrimidinyl-<benzothiazolyl- $<$ benzylbenzimidazolyl formazanes. The results of the calculations are presented in Table 4 
Table 4. Dipole moments and values of «softness» of the formazanes studied

\begin{tabular}{c|c|c|c|c|c|c|c|c|c}
\hline Compound № & I & II & III & IV & V & VI & VII & VIII & IX \\
\hline $\mathrm{S} \cdot 10^{3}$ & 1.476 & 1.457 & 1.452 & 1.524 & 1.429 & 1.538 & 1.402 & 1.404 & 1.375 \\
$\mu, \mathrm{D}$ & 2.99 & 2.43 & 3.48 & 4.42 & 1.03 & 4.26 & 6.18 & 5.43 & 8.61 \\
\hline
\end{tabular}

Despite similar values of physical and chemical parameters of the compounds (Tab. 4), under the same conditions 1-(4-carboxyphenyl)-3-methyl-5-(4,6-diphenylpyrimidine-2-yl)formazan has a greater dipole moment and consequently it is kept stronger on the RH-cellulose matrix than the others. By diffuse reflection spectroscopy in the IR region, it is shown that the "soft" modification of benzazolyl- and diphenylpyrimidinylformazanes on a cellulosecontaining matrix involves sterically more accessible hydroxyl groups in the atom (C-3) of cellulose. Using the diffuse reflectance spectroscopy in the infrared spectrum, it was shown that sterically more accessible hydroxyl groups of the C-3 atom in the cellulose molecule are involved into the «soft» immobilization of benzazolyl- and diphenylpyrimidinyl formazanes onto the cellulose matrix.

In addition it was found that the modification of cellulose matrices (due to the steric requirements of the carriers and the substituents in the formazan molecule) resulted to formation of immobilized hetarylformazan reagents with the certain form. The fact that the matrix colour and colour of the initial ethanol solutions of the reagents were identical to each other gave evidence that fixed dimethyl-pyrimidinyl-substituted formazanes $(\mathrm{pKa}=10-12)$ were in ionized state. However, immobilizing benzothiazolylformazanes $(\mathrm{pKa}=6-8)$ resulted to a bathochromic shift the carrier colour $(\Delta \lambda=10-25 \mathrm{~nm})$ in comparison to initial solutions of the reagents. That was evidence that benzothiazolylformazanes were in partly ionized state [21].

Due to the high content of carboxyl groups, formazanes immobilized onto the RH-cellulose matrix were strongly kept and formed deeply coloured compounds when reacting with aqueous solutions of metal salts $\mathrm{Cu}$ (II), $\mathrm{Hg}(\mathrm{II}), \mathrm{Zn}(\mathrm{II})$ and $\mathrm{Pb}(\mathrm{II})(\Delta \lambda=80-180 \mathrm{~nm})$. While studying sorption analytical characteristics of the used sorbents, it was observed that the sorption capacity and the maximum extraction efficiency for ions of $\mathrm{Co}$ (II), $\mathrm{Ni}$ (II), $\mathrm{Cu}$ (II), $\mathrm{Hg}(\mathrm{II}), \mathrm{Zn}(\mathrm{II}), \mathrm{Cd}(\mathrm{II}), \mathrm{Ni}(\mathrm{II})$, and $\mathrm{Pb}(\mathrm{II})$ depended on the heterocycle of a formazan immobilized and the efficiency increases in the series: benzothiazolyl- $<$ pyrimidinyl- $<$ benzylbenzimidazolyl.

Study of immobilizing formazanes I-IX onto RHOS-cellulose matrices showed that formazan groups were weakly kept and were leached by the flow of the analyzed solution of metal salts.

While reacting with aqueous solution of metal salts, the RH-matrix surfaces 1-9 change their initial colour, which allows to detect visually the presence of $\mathrm{Cu}$ (II), $\mathrm{Hg}(\mathrm{II}), \mathrm{Zn}$ (II) and $\mathrm{Pb}$ (II) ions in the solution at the concentration not less than $1.0 \mu \mathrm{g} / \mathrm{cm}^{3}$. However, when increasing metal concentration, the change of staining intensity of the matrices of the sorbents 1-5, 8 is not observed. The phenomena allowed to develop test-forms for rapid detection of $\mathrm{Cu}(\mathrm{II}), \mathrm{Hg}(\mathrm{II}), \mathrm{Zn}(\mathrm{II})$, and $\mathrm{Pb}(\mathrm{II})$ ions in pure solutions and water systems.

The scanning electronic microscopy (SEM) which use secondary electrons with different zooms in natural state was used for investigation of structural changes in the RH cellulose matrix and the sorbent 9 modified by 1 (4-carboxyphenyl)-3-methyl-5-(4,6-diphenylpyrimidine-2-yl) formazan (Fig. 2). It has been established that RH cellulose matrix is characterized by a dense adhesion between fibrillated epidermal fibers and bast ones (Fig. 2a). Formazan IX immobilized is seen on the fiber surface of RH cellulose matrix as light both small-sized $(<1 \mathrm{mcm})$ and large-sized (up to $3 \mu \mathrm{m}$ ) particles which are unequally distributed (Fig. 2b). After the interaction between the sorbent 9 and aqueous solution of mercury (II) acetate, the HR surface morphology became loose, along with appearing the formazan particles and particles of $\sim 5 \mu \mathrm{m}$ in size. Apparently, the formed chelate mercury(II) complexes form clusters or agglomerates (Fig. 2c).

Since no noticeable changes in their color were observed during the interaction with salt solutions of $\mathrm{Cu}$ (II), $\mathrm{Hg}(\mathrm{II}), \mathrm{Zn}(\mathrm{II})$, and $\mathrm{Pb}(\mathrm{II})$ for sorbents 1-5, 8, for further studies, sorbents 6, 7, and 9 were used as SPRIS, characterized by a noticeable bathochromic change in the color of solid-phase SPRIS reagents upon complexation.

\section{Development of test analysis methods using cellulose-containing matrices}

\subsection{Study of the obtained SPRIS (1 ${ }^{\text {st }}$ method) for water safety control}

Sorbents 7 and 9 having 1-phenyl and 1-(4-carboxyphenyl)-3-methyl-5-(4,6-diphenylpyrimidine-2-yl)formazane immobilized onto the HR-cellulose matrix can be used to develop SPRIS for express determination of mercury(II) in waste and natural waters in the range of $2-30 \mathrm{mg} / \mathrm{dm}^{3}$ and $2-46 \mathrm{mg} / \mathrm{dm}^{3}$, respectively. When determining the content of lead(II) ions using sorbent 6 modified by 1-(2-tolyl)-3-ethyl-5-(benzylbenzimidazole-2-yl)formazan VI, the detection limit was $0.04 \mathrm{mg} / \mathrm{dm}^{3}$. 

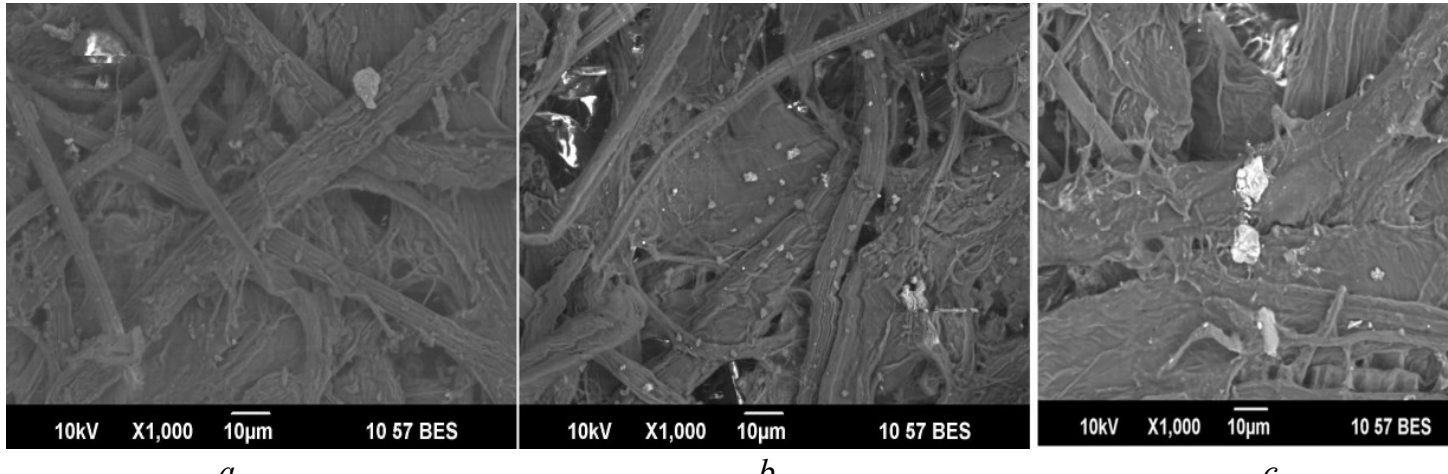

c

Fig. 2. Microphotographs of the RH-cellulose matrix surface obtained by SEM, zoom in 1000 times: $a$ ) the initial RH-cellulose matrix; $b$ ) the sorbent $9 ; c$ ) after the interaction between the sorbent 9 and aqueous solution of mercury(II) acetate

Mercury(II) contents in the model solution, natural waters, as well as in specimen of snow taken in Oktyabrskiy district, Ekaterinburg, Russian Federation, were determined. The results of the study are presented in table 5. The correctness of the developed method has been proved by the analysis of spiked samples, using the water from the Iset River and the water from melted snow as a basis (background) to obtain a solution with a given concentration of the metal being determined. A satisfactory agreement between the data of visual determination and the results of quantitative analysis, including inversion voltammetry, has been shown.

Table 5. Mercury(II) contents in the model solution, natural waters, as well as in specimen of snow taken in Oktyabrskiy district, Ekaterinburg, Russian Federation, ( $\mathrm{n}=5 ; \mathrm{P}=0.95)$

\begin{tabular}{|c|c|c|c|c|}
\hline Object of analysis & Method & Introduced, $\mathrm{mg} / \mathrm{dm}^{3}$ & Found, $\mathrm{mg} / \mathrm{dm}^{3}$ & Relative standard deviation $\mathrm{Sr}$ \\
\hline \multirow{15}{*}{ Model solution } & \multirow{5}{*}{$\begin{array}{l}\text { Test-determination } \\
\text { using SPRIS with } \\
\text { sorbent } 7\end{array}$} & 2.1 & $2.0 \pm 0.1$ & 0.23 \\
\hline & & 4.6 & $4.7 \pm 0.2$ & 0.18 \\
\hline & & 8.7 & $8.0 \pm 0.5$ & 0.23 \\
\hline & & 16.5 & $16.0 \pm 0.6$ & 0.24 \\
\hline & & 32.3 & $32.0 \pm 0.4$ & 0.13 \\
\hline & \multirow{5}{*}{$\begin{array}{l}\text { Spectrophotometric } \\
\text { method }\end{array}$} & 2.1 & $2.00 \pm 0.08$ & 0.125 \\
\hline & & 4.6 & $4.68 \pm 0.05$ & 0.068 \\
\hline & & 8.7 & $8.80 \pm 0.05$ & 0.046 \\
\hline & & 16.5 & $16.60 \pm 0.05$ & 0.034 \\
\hline & & 32.3 & $32.5 \pm 0.06$ & 0.056 \\
\hline & \multirow{5}{*}{$\begin{array}{c}\text { Inversion } \\
\text { voltammetry }\end{array}$} & 2.1 & $2.000 \pm 0.003$ & 0.106 \\
\hline & & 4.6 & $4.705 \pm 0.002$ & 0.034 \\
\hline & & 8.7 & $8.695 \pm 0.005$ & 0.015 \\
\hline & & 16.5 & $16.500 \pm 0.001$ & 0.014 \\
\hline & & 32.3 & $32.300 \pm 0.001$ & 0.016 \\
\hline \multirow{9}{*}{$\begin{array}{l}\text { Samples of the } \\
\text { water of the Iset } \\
\text { river }\end{array}$} & \multirow{3}{*}{$\begin{array}{l}\text { Test-determination } \\
\text { using SPRIS with } \\
\text { sorbent } 7 \\
\end{array}$} & 2.0 & $2.1 \pm 0.5$ & 0.20 \\
\hline & & 4.0 & $4.2 \pm 0.5$ & 0.17 \\
\hline & & 8.0 & $8.5 \pm 0.5$ & 0.14 \\
\hline & \multirow{3}{*}{$\begin{array}{l}\text { Spectrophotometric } \\
\text { method }\end{array}$} & 2.0 & $2.10 \pm 0.05$ & 0.108 \\
\hline & & 4.0 & $4.05 \pm 0.05$ & 0.117 \\
\hline & & 8.0 & $8.10 \pm 0.07$ & 0.114 \\
\hline & \multirow{3}{*}{$\begin{array}{l}\text { Inversion } \\
\text { voltammetry }\end{array}$} & 2.0 & $2.000 \pm 0.003$ & 0.020 \\
\hline & & 4.0 & $4.050 \pm 0.005$ & 0.013 \\
\hline & & 8.0 & $8.010 \pm 0.007$ & 0.018 \\
\hline \multirow{9}{*}{$\begin{array}{l}\text { Samples of snow } \\
\text { cover }\end{array}$} & \multirow{3}{*}{$\begin{array}{l}\text { Test-determination } \\
\text { using SPRIS with } \\
\text { sorbent } 7\end{array}$} & 2.0 & $2.3 \pm 0.5$ & 0.12 \\
\hline & & 4.0 & $4.2 \pm 0.5$ & 0.23 \\
\hline & & 8.0 & $7.5 \pm 0.5$ & 0.24 \\
\hline & \multirow{3}{*}{$\begin{array}{l}\text { Spectrophotometric } \\
\text { method }\end{array}$} & 2.0 & $2.15 \pm 0.05$ & 0.095 \\
\hline & & 4.0 & $4.10 \pm 0.08$ & 0.108 \\
\hline & & 8.0 & $8.15 \pm 0.08$ & 0.116 \\
\hline & \multirow{3}{*}{$\begin{array}{c}\text { Inversion } \\
\text { voltammetry }\end{array}$} & 2.0 & $2.000 \pm 0.006$ & 0.034 \\
\hline & & 4.0 & $4.030 \pm 0.003$ & 0.012 \\
\hline & & 8.0 & $8.000 \pm 0.003$ & 0.054 \\
\hline
\end{tabular}




\subsection{Study of the possibility of using cellulose-containing matrices for the concentration of metal ions with} subsequent development with a solution of formazans ( $2^{\text {nd }}$ method)

It is known that the sensitivity, selectivity and accuracy of the determination of the toxic metal ion content in natural aqueous media using SPRIS is often influenced by the matrix composition of specimens as well as low concentrations. In this case, using preconcentration allows to determine concentrations of trace elements in salt solution of different metals, reduce the determination limits, avoid or reduce significantly the influence of background macronutrients thereby increase the selectivity, sensitivity of the analysis and reduce the time of the analysis.

In addition, preconcentration allows simultaneous testing several variants of the «revealing» method for preliminary sorbed metal ions on the matrix, thereby expanding the range of used formazanes contributing to finding a unique combination of matrix, metal ion and highly sensitive reagent.

To determine the parameters which characterize the maximum sorption capacity of sorbents, the isotherms for adsorption of metal ions in aqueous solutions onto RH-cellulose matrix metal ions under static conditions were obtained by stirring and thermostating in the temperature range $(295 \pm 5) \mathrm{K}$ (Fig. 3). The initial and current metal ion concentrations were determined by the method of inversion voltammetry (voltammetric analyzer IVA-5, Russia).

High hydrophilicity of cellulose matrices, a large number of amorphous areas, and high content of carboxyl groups (89.8\%) in RH-cellulose matrices facilitate to easier penetration and strong "fixing" of sorbed ions $\mathrm{Cu}(\mathrm{II})$, $\mathrm{Ni}(\mathrm{II}), \mathrm{Zn}(\mathrm{II}), \mathrm{Cd}(\mathrm{II})$ and $\mathrm{Pb}(\mathrm{II})$ on their surface.

According to the obtained data, the maximum adsorption capacity $\left(\mathrm{a}_{\max }\right)$ for metal ions calculated by Langmuir equation is $86.92 ; 68.20 ; 70.05 ; 59.35 ; 84.23 \mathrm{mmol} / \mathrm{kg}$ for $\mathrm{Cu}$ (II), Ni(II), $\mathrm{Zn}$ (II), $\mathrm{Cd}$ (II) and $\mathrm{Pb}$ (II), respectively. When reacting metal ions fixed on the matrix with hetarylformazan solutions («revealing» method), deeply coloured compounds are formed $(\Delta \lambda=80-180 \mathrm{~nm}$ ). It is shown the possibility of developing SPRIS for the express determination of mercury(II) concentration using 1-(4-carboxyphenyl)-3-methyl-5-(4,6-diphenylpyridine)formazan IX and 1-(4-carboxyphenyl)-3-isopropyl-5-(benzoxazol-2-yl)formazan IV on the base of RH-cellulose matrices to use in wastewater in the range of $2.0-46,0 \mathrm{mg} / \mathrm{cm}^{3}$. The lower limit of mercury(II) determined using 1-(4-carboxyphenyl)-3-isopropyl-5-(benzoxazole-2-yl)formazane is $0.05 \mathrm{mg} / \mathrm{dm}^{3}$. When determining the content of lead(II) ions using 1-(2-tolyl)-3-ethyl-5-(benzylbenzimidazole-2-yl)formazane, determination limit is $0.04 \mathrm{mg} / \mathrm{dm}^{3}$. Concentrations of $\mathrm{Zn}(\mathrm{II}), \mathrm{Ni}(\mathrm{II}), \mathrm{Co}(\mathrm{II}), \mathrm{Cd}(\mathrm{II})$ exceeding the content of the analyzed ions by 5 times don't interfere to the determination. The duration of the determination procedure does not exceed 15 minutes.

It was found that when using «revealing» method by hetarylformazan solution, the time to develop the maximum chromogenic effect depends not only on a metal ion sorbed onto a cellulose matrix but on the nature of the formazan heterocycle as well. Thus, when using 1-(2-tolyl)-3-ethyl-5-(benzylbenzimidazole-2-yl)formazan VI (optimal concentration is $0.018 \mathrm{mmol} / \mathrm{dm}^{3}$ ) to determine the content of mercury ions(II), the colour at the solution $\mathrm{pH}$ $5.5 \pm 0.3$ develops within 1-2 minutes, while when visual determining lead ions(II) at the solution $\mathrm{pH} 6.5 \pm 0.3$, the matrix gets coloured instantly. In the case of applying 1-(4-carboxyphenyl)-3-isopropyl-5-(benzoxazole-2-yl)formazane solution (optimal concentration is $0.01 \mathrm{mmol} / \mathrm{dm}^{3}$ ) onto a matrix which contain mercury or lead ions the colour develops instantly.

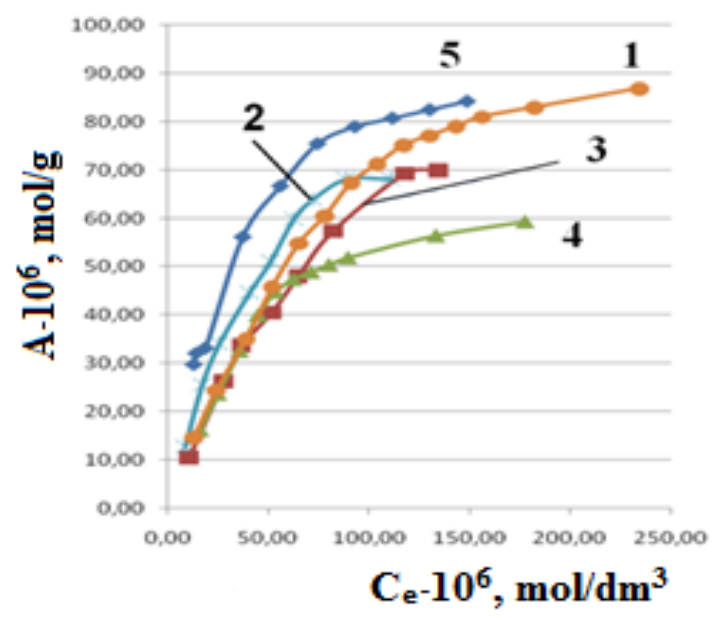

Fig. 3. Sorption of metal ions on RH-cellulose matrix: 1 - copper (II), 2 - nickel (II), 3 - zinc (II), 4 - cadmium (II), 5 - lead (II) 
The negatively charged surface of cellulose fibres [27-29], which is the basis of RHOS-cellulose matrix, effectively absorbs lead ions $\left(\mathrm{a}_{\max }=80.7 \mathrm{mmol} / \mathrm{kg}\right)$. The interaction of fixed $\mathrm{Pb}$ (II) ions with 1-(2-hydroxy-5-nitrophenyl)-3-ethyl-5-(benzoxazole-2-yl)formazan solution results to the formation of an chelate complexes with $\mathrm{Pb}$ (II) ions, which is manifested on a white background of the matrix by greenish-blue staining, thereby the compound is easily determined by the observer with an error not more than $15 \%$. Developing the chromogenic effect is available when the concentration of $\mathrm{Pb}$ (II) ions $\geq 0.5 \mathrm{mg} / \mathrm{dm}^{3}$, however, the presence of $\mathrm{Ni}$ (II) ions, ratio $1: 1$, interferes to determine correctly.

When the cellulose matrices have different strength characteristics they can be superimposed on each other in the flow cell to perform simultaneous sorption of different elements. It should be noted that it is possible to concentrate 2-3 elements on each cellulose matrix with following determination of each of them by the "development" reaction with a suitable organic reagent. The authors showed SPRIS synthesis routs on RHOS-cellulose matrices using this method of test-determination of mercury(II) and copper(II) in natural waters with the use of 1-(4carboxyphenyl)- and 1-phenyl-3-methyl-5-(4,6-diphenylpyrimidine-2-yl)formazanes. According to calculations, the lower limit of mercury(II) is $0.06 \mathrm{mg} / \mathrm{dm}^{3}$, copper(II) is $0.05 \mathrm{mg} / \mathrm{dm}^{3}$.

The developed SPRIS were tested on various real objects: natural and rain waters, snow cover, washing the leaves of trees placed on the city highways. A satisfactory agreement between the visually determined data and the results of quantitative analysis in the mean value depreciation area of the standard scale is shown. Metrological characteristics indicate their correctness and absence of systematic errors.

\section{Conclusion}

1. The combinations of chromogenic reagents and cellulose matrices presented in this paper allow regulating the sensitivity and selectivity of test-systems. While studying sorption analytical characteristics of used RH-cellulose sorbents, it was observed that the sorption capacity and the maximum extraction efficiency for ions of Co(II), $\mathrm{Ni}(\mathrm{II}), \mathrm{Cu}(\mathrm{II}), \mathrm{Hg}$ (II), $\mathrm{Zn}$ (II), $\mathrm{Cd}(\mathrm{II}), \mathrm{Ni}(\mathrm{II})$, and $\mathrm{Pb}$ (II) depended on the heterocycle of a formazan immobilized and the efficiency increases in the series: benzothiazolyl- $<$ pyrimidinyl- $<$ benzylbenzimidazolyl. Study of immobilizing formazanes onto RHOS-cellulose matrices showed that formazan groups were weakly kept and were leached by the flow of the analyzed solution of metal salts.

2. Solid-phase reactive indicator systems (SPRIS) were developed for determination of metal ions. Sorbents having 1-phenyl and 1-(4-carboxyphenyl)-3-methyl-5-(4,6-diphenylpyrimidine-2-yl)formazane immobilized onto the HR-cellulose matrix can be used for express determination of mercury(II) in waste and natural waters in the range of 2-30 mg/ $\mathrm{dm}^{3}$ and 2-46 mg/dm3, respectively. When determining the content of lead(II) ions using sorbent modified by 1-(2-tolyl)-3-ethyl-5-(benzylbenzimidazole-2-yl)formazan, the detection limit was $0.04 \mathrm{mg} / \mathrm{dm}^{3}$. It was found that when using «revealing» method by hetarylformazan solution, the time for developing the maximum chromogenic effect depends not only on a metal ion sorbed onto a cellulose matrix but on the nature of the formazan heterocycle as well. Thus, when using 1-(2-tolyl)-3-ethyl-5-(benzylbenzimidazole-2-yl)formazan (optimal concentration is $0.018 \mathrm{mmol} / \mathrm{dm} 3$ ) to determine the content of mercury ions(II), the colour at the solution $\mathrm{pH} 5.5 \pm 0.3$ develops within 1-2 minutes, while when visual determining lead ions(II) at the solution $\mathrm{pH} 6.5 \pm 0.3$, the matrix gets coloured instantly.

3. Due to their small size, rapidity, and energy saving, the systems SPRIS can be successfully used in on-line mode, which has crucial importance for the controlling environmental objects in emergency management.

\section{References}

1. Materialy iz netraditsionnykh vidov volokon: tekhnologii polucheniya, svoystva, perspektivy primeneniya [Materials from non-traditional types of fibers: production technologies, properties, application prospects], ed. A.V. Vurasko. Yekaterinburg, 2020, 252 p. (in Russ.).

2. Simonova Ye.I. Polucheniye i svoystva sorbtsionnykh materialov na osnove tekhnicheskoy tsellyulozy iz nedrevesnogo rastitel'nogo syr'ya: diss. ... kand. tekhn. nauk. [Obtaining and properties of sorption materials based on technical cellulose from non-woody plant raw materials: diss. ... Cand. tech. sciences]. Yekaterinburg, 2018, 167 p. (in Russ.).

3. Meena P.L., Saxena R., Sharma N. International Journal of Agriculture and Food Science Technology, 2014, vol. 5, no. 4, pp. 287-296.

4. Etorki A.M., Shaban I.S. American Journal of Environmental Protection, 2015, vol. 4, no. 2, pp. 105-109. DOI: 10.11648/J.AJEP.20150402.16. 
5. Repo E., Warchoł J.K., Sillanpää M. Journal of Sustainable Development of Energy. Water and Environment Systems, 2017, vol 5, no. 1, pp. 89-100. DOI: 10.13044/j.sdewes.d5.0135.

6. Castro G.R., Cristante V.M., Padilha C.C.F., Jorge S.M.A., Florentino A.O., Prado A.G.S., Padilha P.M. Microchimica Acta, 2008, vol. 160, pp. 203-209. DOI:10.2478/v10026-010-0002-5.

7. Castro R.S.D., Caetano L., Ferreira G., Padilha P.M., Saeki M.J., Zara L.F., Martines M.A.U., Castro G.R. Industrial and Engineering Chemistry Research, 2011, vol. 50, pp. 3446-3451. DOI:10.1021/ie101499e.

8. Yan L., Wang Y., Chen J. Journal of Applied Polymer Science, 2008, vol. 110, no. 3, pp. 1330-1335. DOI:10.1002/app.28562.

9. Łukaszczyk J., Łẹkawska E., Lunkwitz K., Petzold G. Journal of Applied Polymer Science, 2004, vol. 92, no. 3, pp. 1510-1515. DOI:10.1002/app.20082.

10. Progress $v$ khimii formazanov [Progress in the chemistry of formazans], ed. I.N. Lipunov, G.I. Sigeykin. Moscow, 2009, 296 p. (in Russ.).

11. Pervova I.G., Skorykh T.V., Maslakova T.I., Mel'nik T.A., Lipunova G.N., Lipunov I.N., Wang Li, Chen Chen. Journal of Shenyang University of Chemical Technology, 2011, no. 2, pp. 183-191. DOI: 10.1134/S1070363218120423.

12. Şenöz H. Hacettepe Journal of Biology and Chemistry, 2012, vol. 40, no. 3, pp. 293-301.

13. Vurasko A.V., Simonova E.I., Glukhikh V.V., Minakova A.R. CEUR workshop proceedings Cep. "CSASE 2018 Proceedings of the Annual Scientific International Conference on Computer Systems, Applications and Software Engineering" 2018. 2018 Annual scientific international conference on computer systems, applications and software engineering, CSASE 2018. Nizhniy Tagil, 2018, pp. 7-16.

14. Shapovalova I., Vurasko A., Petrov L., Kraus E., Heinrich L., Michael H., Stoyanov O. Journal of Applied Polymer Science, 2018, vol. 135, no. 5, 45796. DOI: 10.1002/app.45796.

15. Vurasko A.V., Simonova Ye.I., Minakova A.R. Izvestiya Sankt-Peterburgskoy lesotekhnicheskoy akademii, 2019, no. 226, pp. 139-154. DOI: 10.21266/2079-4304.2019.226.139-154. (in Russ.).

16. GOST 7690-76. Tsellyuloza, bumaga i karton. Metod opredeleniya belizny [GOST 7690-76. Pulp paper and board. Method of determination of brightness]. Moscow, 1999, 7 p. (in Russ.).

17. Uchiumi A., Takatsu A., Tanaka H. Analytical sciences, 1991, vol. 7, pp. 459-462.

18. Buzykin B.I., Lipunova G.N., Sysoyeva L.P., Rusinova L.I. Khimiya formazanov. [Chemistry of formazans]. Moscow, 1992, 376 p. (in Russ.).

19. Chemical Pulping Part 1, Fibre Chemistry and Technology/ Paper Engineers' Association / Paperi ja Puu Oy, Helsinki, 2011, 748 p.

20. Fengel D., Wegener G. Wood-Chemistry, ultrastructure, reactions. Walter de Gruyter, Berlin, Germany, 1989, 613 p.

21. Liu S., Tao D., Bai H., Liu X. Journal of Applied Polymer Science, 2012, vol. 126, pp. E281-E289. DOI: 10.1002/app.36637.

22. Maslakova T.I., Pervova I.G., Zhelnovach A.V., Maslakov P.A., Simonova Ye.I., Vurasko A.V. Sorbtsionnyye $i$ khromatograficheskiye protsessy, 2017, vol. 17, no. 3, pp. 398-406. (in Russ.).

23. Al-Araji Y.H., Shneine J.K., Ahmed A.A. International Journal of Research in Pharmacy and Chemistry, 2015, vol. 5, no. 1, pp. 41-76.

24. Maslakova T.I., Pervova I.G., Maslakov P.A., Simonova Ye.I., Vurasko A.V. Sorbtsionnyye i khromatograficheskiye protsessy, 2016, vol. 16, no. 6, pp. 847-857. (in Russ.).

25. Jensen F. Introduction to Computational Chemistry, Third Edition, Wiley, 2017, 661 p.

26. Ramos-Morales F.R., Durand-Niconoff S., Correa-Basurto J., Meléndez-Bustamante F.J., Cruz-Sánchez J.S. The Journal of the Mexican Chemical Society, 2008, vol. 52, no. 4, pp. 241-248. DOI: 10.1007/s12039-011-0119-y.

27. Jamshaid A., Hamid A., Muhammad N., Naseer A., Ghauri M., Iqbal J., Rafiq S., Shah N.S. ChemBioEng Reviews, 2017, no. 4, pp. 1-18. DOI: 10.1002/cben.201700002.

28. Madivoli E.S., Kareru P.G., Gachanja A.N., Mugo S., Murigi M.K., Kairigo P.K., Kipyegon C., Mutembei J.K., Njonge F.K. International Research Journal of Pure \& Applied Chemistry, 2016, vol. 12, no. 3, pp. 1-9. DOI: 10.9734/IRJPAC/2016/28548.

29. Wang Z., Hauser P.J., Rojas O.J. Journal of Research, 2015, vol. 2, no. 2, pp. 13-19. DOI: 10.14504/ajr.2.2.2.

Received April 24, 2021

Revised October 6, 2021

Accepted October 23, 2021

For citing: Maslakova T.I., Vurasko A.V., Pervova I.G., Maslakov P.A., Aleshina L.V., Shapovalova I.O. Khimiya Rastitel'nogo Syr'ya, 2021, no. 4, pp. 351-359. (in Russ.). DOI: 10.14258/jcprm.2021049485. 
